\title{
In the peeng
}

Welcome to the May 2010 issue of CERL News. The Butler University Bulldogs were one of the most compelling stories of this year's NCAA men's basketball tournament, advancing to the championship game against Duke. Many schools, like Butler, take advantage of the popularity of student-athletes on campus to help promote the library. Teresa Williams discusses Butler's "Promotions with student-athletes" this month and provides advice on being compliant with NCAA rules.

While student testimonials are a great way to get the word out about library services, stories from library employees can add to the sense of history of the library and campus. David Bynog and Jane Zhao write about a video project capturing reflections on library history from staff members in "Telling our own story."

More traditional storytelling formed the basis for a writing assignment focused on biography at Westminster University. Erin Smith and Dorita Bolger discuss the program in their article "Taking it personally." The University of Florida Marston Science Library helped tell the story of the "Elegance of science" through visuals by holding a scientific art contest, as outlined by Amy Buhler and Valrie Davis.

Many new librarians will be graduating from MLIS programs in the coming months. René Tanner provides advice for "Making the most of your new career" this month. And congratulations to all the graduates!

Make sure to take a look at all of the other great articles and columns, including a discussion of Bermuda College's visiting librarian program and Internet Resources on "Disability Studies." This month's issue also includes a handy pullout section of ACRL programs at the upcoming ALA Annual Conference in Washington, D.C. We hope to see you June 24-29!

- David Free, editor-in-chief dfree@ala.org

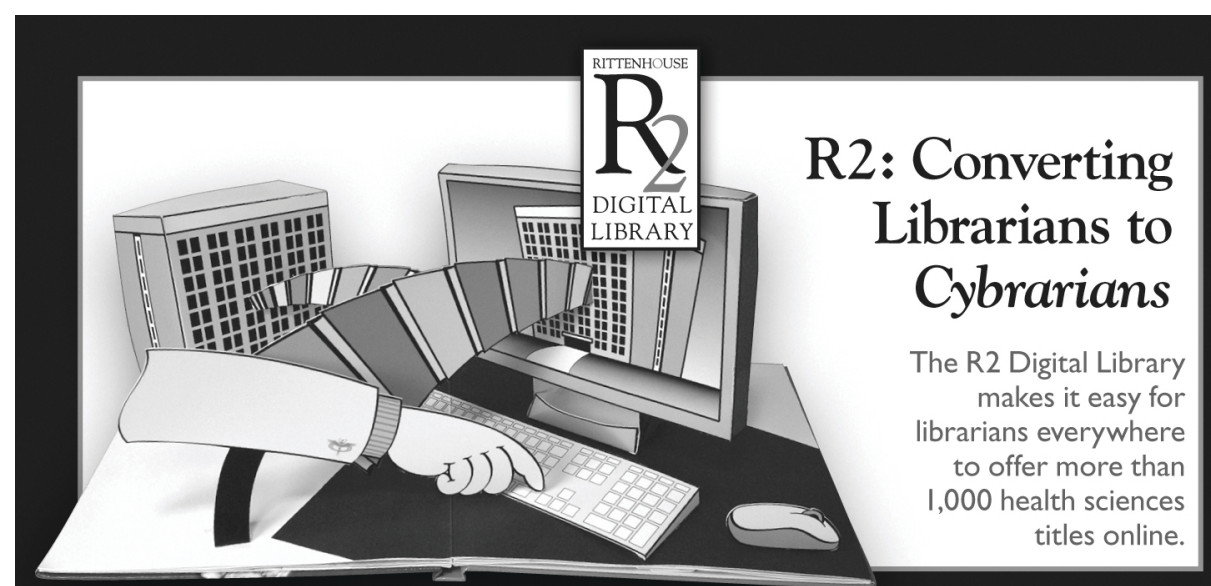

SAVE MONEY.

Avoid "all-or-nothing" prices. Add more titles immediately with the push of a button.

\section{SAVE TIME.}

Easy-to-use interface. If you can surf the web, you can use R2.

\section{MANAGE SMARTLY.}

Monitor usage statistic in real time, so you can make informed decisions.

\section{Rittenhouse} B OOK DISTRIBUTORS
5 II Feheley Dr., King of Prussia, PA $19406 \cdot 800-345-6425$ www.r2library.com - www.rittenhouse.com 